\title{
Dapsone-resistant Leprosy in Ethiopia
}

\author{
J. M. H. PEARSON*†, G. S. HAILE*, R. St C. BARNETSON* \\ Medical Research Council Leprosy Project, \\ Addis Ababa, Ethiopia \\ and \\ R. J. W. REES \\ National Institute for Medical Research, \\ London NW7 1AA, England
}

\begin{abstract}
During the 5 years 1973-1977, 254 patients suspected of developing dapsoneresistant leprosy were seen in the Addis Ababa area. They were drawn from a pool of about 1500 registered patients with lepromatous leprosy, giving an incidence of about $3 \%$ per annum (among patients at risk). Fifty-one were proved resistant by mouse foot-pad tests, and 57 more by clinical trial. The remainder, who continued in trial treatment, conformed to the clinical pattern of those proved to be dapsone resistant. Only 2 patients were proved to be sensitive to dapsone.

In addition, among 106 suspected cases from elsewhere in Ethiopia giving a "classical" history, 28 were proved resistant by mouse foot-pad tests, and only one was dapsone sensitive. Eleven out of 17 patients who relapsed having discontinued dapsone treatment were also found to have developed dapsone-resistant leprosy ( 7 by mouse foot-pad tests, and 4 more by clinical trial): 2 were sensitive to dapsone.

Mouse foot-pad testing for primary dapsone-resistant leprosy was performed in 29 patients. Fourteen lived in the Addis Ababa area; 5 of them were resistant. Fifteen came from elsewere in Ethiopia; 11 were resistant. Dapsone-resistant leprosy has become so widespread in Ethiopia as to threaten the practical possibility of leprosy control by chemotherapy alone.
\end{abstract}

\section{Introduction}

Dapsone has been used for over 30 years to treat leprosy, and remains by far the most suitable and widely used drug for field therapy. The widespread emergence of dapsone-resistant strains of Mycobacterium leprae would require

* Present addresses. J. M. H. Pearson: National Institute for Medical Research, London NW7 1AA, England. G. S. Haile: Addis Ababa Leprosy Hospital, PO Box 165, Addis Ababa, Ethiopia. R. St C. Barnetson: Department of Dermatology, The Royal Infirmary, Edinburgh EH3 9YW, Scotland.

$\dagger$ Requests for reprints should be addressed to JMHP at the National Institute for Medical Research, London NW7 1AA, England.

Received for publication 27 February, 1979. 
major changes in the practice of leprosy control. It is important, therefore, to obtain data on dapsone resistance in a form that can be utilized for planning leprosy control programmes. This essentially means accurate determination of the prevalence (and if possible incidence) of resistant cases in a defined area.

This paper represents such a study. The Medical Research Council Leprosy Project in the Addis Ababa Leprosy Hospital was initiated in January 1973. From then until its closure in August 1978 the Project had a special interest in dapsone-resistant leprosy, and was fortunate to have assistance from colleagues both inside and outside the hospital, who referred all suspected cases to the Project for assessment. This paper, therefore, includes information on all patients who were suspected of developing dapsone-resistant leprosy and who attended the Addis Ababa Leprosy Hospital for investigation and treatment during the 5 year period 1973-1977. However, particular emphasis is given to the findings among patients registered for treatment in the Addis Ababa area, where closer surveillance was possible and ensured that every patient suspected of developing dapsone-resistant leprosy was studied by the MRC Project, and enabled accurate prevalence and incidence figures to be obtained.

The first reports of proven dapsone-resistant leprosy came from studies in an inpatient institution (Pettit and Rees, 1964). The figure given for prevalence was probably correct at that time, though many new cases have subsequently been diagnosed (Pearson et al., 1975), but the size of the problem which might develop in the future was seriously underestimated. In Ethiopia, preliminary reports have indicated both that the prevalence of acquired resistance may be significantly greater than had been observed elsewhere, and also that primary dapsone resistance may be not uncommon (Pearson et al., 1976, 1977). These preliminary findings are confirmed and amplified in this paper. If dapsoneresistant leprosy is a half, or even a quarter as frequent elsewhere as it is in Ethiopia, the practicability of leprosy control by chemotherapy alone must be considered as seriously in doubt.

\section{Materials and Methods}

The patients included in this study may be considered as comprising two major groups:

\section{PATIENTS LIVING IN THE ADDIS ABABA AREA}

Prior to their referral to the MRC Project, these patients were all routinely treated on an outpatient basis, using oral dapsone, unless they developed some complication requiring hospitalization. Most attended a clinic (either in the Addis Ababa Leprosy Hospital or a city Municipal Clinic) once a month; at this visit they were seen by a paramedical worker, and their treatment issued. Every 6 months, however, they attended the "Review Clinic" in the hospital, where they were seen by a doctor, and treatment for the next 6 months prescribed. Most of the Addis Ababa patients included in this study were ref erred for assessment from the Review Clinic. 


\section{PATIENTS FROM ELSEWHERE IN ETHIOPIA}

These patients attended clinics in country towns or market villages, and seldom or never saw a doctor. Those included in this study were either referred to the Addis Ababa Leprosy Hospital by the worker in charge of the clinic, or in some cases referred themselves because they were not satisfied with their progress.

Patients from Addis Ababa were usually seen within a few months of developing symptoms or signs suggestive of dapsone resistance, whereas patients from outside Addis Ababa tended to have more advanced disease by the time they reached the hospital. Once there was suspicion of dapsoneresistant leprosy, however, all patients reaching the hospital were referred to the MRC Project for assessment and management. This report therefore includes all suspected cases of dapsone-resistant leprosy from the Addis Ababa area, but only random cases from the rest of Ethiopia.

Most patients gave the "classical" history of dapsone resistance; that is, initial improvement followed by deterioration despite continued treatment. However, a number of patients were studied who had relapsed because their treatment had been discontinued. Other atypical suspected cases included patients with reactions developing much later than usual in the course of treatment; and patients who, without definite relapse, appeared to show less improvement than would be expected from the duration of treatment.

Many patients had received dapsone in low or irregular dosage. Therefore the majority were started on a period of trial treatment with dapsone in high dosage. Assessments, which were undertaken at the start of the trial and every 6-12 months thereafter, included clinical drawings, skin smears from the most active looking lesions, and biopsies (which, however, were often omitted if the clinical progress and skin smear results were satisfactory).

Patients were not routinely admitted to hospital for treatment; supervision, therefore, amounted in practice to encouragement of the patient to take treatment regularly. This was accomplished in 3 ways:

(1) Increased doctor/patient contact. Addis Ababa patients were seen every 1-2 months by a doctor, usually one of the MRC team.

(2) Health education. The patient was made aware of his problem, the need for the tests was explained, and the fact that we needed his help to establish the correct treatment for him was emphasized.

(3) Alternative presentations of dapsone. Patients who lived close enough to the hospital to attend for weekly injections were offered this treatment. Most other patients received a sugar coated tablet containing dapsone $100 \mathrm{mg}$ : this "new treatment" was supplied directly by the doctor when he saw the patient, and was not available through the hospital pharmacy. Its use appeared to encourage regular clinic attendance and probably also regular daily treatment.

The period of trial treatment was terminated when it was clear that the patient's disease was failing to improve; these patients were considered to have shown clinical proof of dapsone-resistant leprosy. Some patients, however, did not have a period of trial treatment with dapsone, but were changed at once to non-sulphone drugs. Indications for immediate change of treatment included: 
(1) Severe complications, particularly ocular involvement. It was obviously not ethical to risk the patient's eyesight for the sake of clinical proof of drug resistance.

(2) Advanced disease, together with a strong (subjective) impression that the patient was truthful and had been taking dapsone regularly.

(3) Social conditions, particularly the presence of young children in the patient's home.

(4) Patients living in remote areas, who would be unable to return for assessment for a year or so.

These patients were, however, given some priority for mouse foot-pad tests, so that, if the patient proved to have dapsone-sensitive bacilli, he could be changed back to dapsone treatment when the results of the tests became available.

In addition to these investigations of acquired dapsone-resistant leprosy, a programme was undertaken to assess, by mouse foot-pad tests, the prevalence of primary dapsone-resistant leprosy. Patients studied included both residents of Addis Ababa and persons living elsewhere in Ethiopia in areas where antileprosy treatment had been readily available for at least 10 years.

Mouse foot-pad tests were performed using routine methods (Rees, 1967) both in the Addis Ababa Leprosy Hospital (by J.M.H.P.) and in the National Institute for Medical Research, London (by R.J.W.R.). Mice were fed dapsone in the diet from the day of inoculation, and occasional duplicate tests were undertaken to confirm that results from the two laboratories were in agreement.

Because of limited facilities, only a proportion of patients were tested, some at the start of a clinical trial, others when it finished. In some cases, bacilli were screened against a full range of concentration of dapsone in the mouse diet $(0.01 \%, 0.001 \%$ and $0.0001 \%)$; but often only one or two concentrations were used $(0.01 \%$ gives blood levels of dapsone in the mouse in the same range as those in man taking $100 \mathrm{mg}$ daily, and $0.0001 \%$ inhibits multiplication of normal sensitive strains of $M$. leprae).

\section{Results and Comments}

\section{“CLASSICAL” PRESENTATION OF DAPSONE RESISTANCE}

\section{(1) Patients in the Addis Ababa area}

The numbers of patients in the Addis Ababa area with clinical suspicion of dapsone-resistant leprosy seen year by year are shown in Table 1: most of them (220 out of 254) presented with the "classical" history. The number of registered patients with lepromatous leprosy in the Addis Ababa area has been stable at about 1500 for some years; the incidence of suspected cases during this period was therefore about $3 \%$ per annum.

Of the 220 patients with a classical history, 41 (19\%) were advised to discontinue treatment with dapsone at once, and start new treatment: 22 were shown by mouse foot-pad tests to be dapsone resistant. The remaining 179 patients continued to take dapsone for a period of trial treatment. These 
TABLE 1

Number of patients from the Addis Ababa area with suspected dapsone-resistant leprosy seen during the period 1973-77

\begin{tabular}{cccc}
\hline Year & $\begin{array}{c}\text { "Classical” } \\
\text { history }\end{array}$ & $\begin{array}{c}\text { Atypical } \\
\text { presentation }\end{array}$ & Total \\
\hline 1973 & 46 & 3 & 49 \\
1974 & 47 & 9 & 56 \\
1975 & 41 & 7 & 48 \\
1976 & 47 & 8 & 55 \\
1977 & 39 & 7 & 46 \\
Total & 220 & 34 & 254 \\
\hline
\end{tabular}

patients were able to attend the hospital clinic for follow-up regularly, and only 5 have been lost ( 4 by default and 1 by known death). Thus the results of the period of trial treatment for 174 patients are available for analysis.

Seventy-seven patients were female, 97 male: this is not significantly different to the male/female proportion of lepromatous patients under treatment in Addis Ababa. They had received treatment for 2-21 years prior to showing clinical evidence of dapsone resistance (Fig. 1).

Biopsy classification was as follows:

LL, LLp, LLs, LI-130 cases, BL-24 cases, BB- 4 cases,

Not available- 16 cases.

The frequency distribution of the values for averaged Bacterial Index (BI), Morphological Index (MI), and biopsy index and classification were similar for male and female patients.

The initial BI was reported as negative in 2 patients; their biopsies, however, showed "BL active" and "LL resolving" respectively. In the remaining 172 cases the BI was positive, ranging from 0.5 to 6.0 (average 3.5). The MI was

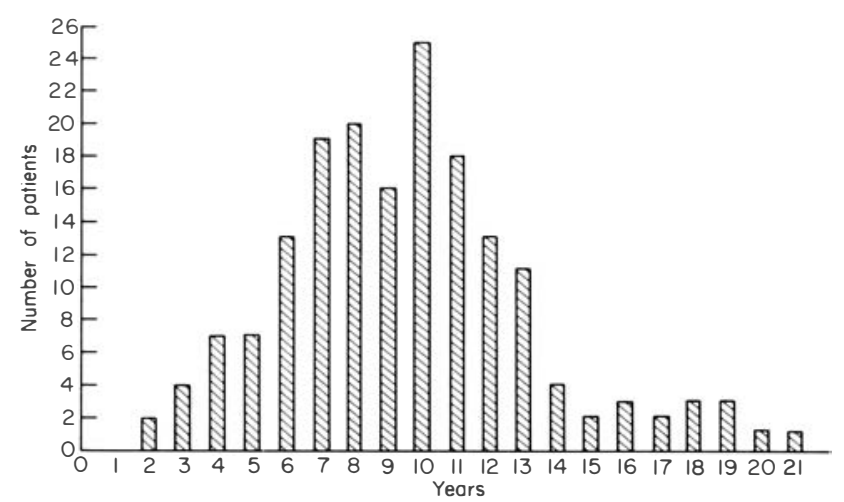

Fig. 1. Time in years from start of treatment with dapsone to emergence of suspected dapsone resistance in 174 patients with lepromatous leprosy. 
TABLE 2

Overall results of period of trial treatment of 174 patients with "classical" history of dapsoneresistant leprosy

\begin{tabular}{lc}
\hline Outcome of trial treatment & Number of patients \\
\hline Clinically resistant, confirmed by mouse foot-pad tests & 25 \\
Clinically resistant, not confirmed by mouse foot-pad tests & 57 \\
Continue in trial, foot-pad tests show dapsone resistance & 4 \\
Continue in trial, foot-pad tests show dapsone sensitivity & 2 \\
Continue in trial, foot-pad test results not available & 86 \\
\hline
\end{tabular}

raised (i.e. solid staining morphologically normal bacilli were observed in the skin smears) in all but 33 cases. Of these 33 , the biopsy was reported as showing histological activity in 23 cases: it was regressional in 4 (including 2 with ENL) and was not available for the remaining 6 cases. Thus, there was evidence of active leprosy, uncontrolled by treatment, in all but 10 cases in the series.

Entry to the trial was spread over 5 years, and patients were assessed every 6-12 months during the trial. Thus, when the trial was reviewed early in 1978, some patients had been studied for a few months only, but some had been followed for as long as 5 years. The overall results at that time are shown in Table 2, and the clinical status of the trial patients at their last assessment in Table 3. About half the patients ( 86 out of 174) had already been shown (clinically or by mouse foot-pad tests) to harbour dapsone-resistant strains of M. leprae, and a further 12 were not doing well clinically. Only 2 were proved by foot-pad tests to be fully sensitive to dapsone. An interesting feature was that as many as 25 patients who started trial treatment in 1973 and 1974 were still doing well.

This prolonged response was related to the treatment the patients had received before they entered the trial. They may be divided into two groups:

"Weekly dosage" group (44 patients).

TABLE 3

Clinical status of 174 trial patients at final

\begin{tabular}{ccccc}
\hline $\begin{array}{c}\text { Start of } \\
\text { trial } \\
\text { (year) }\end{array}$ & $\begin{array}{c}\text { Duration of } \\
\text { follow-up } \\
\text { (years) }\end{array}$ & Total & Improved & Worse \\
\hline 1973 & $4-5$ & 25 & 11 & 14 \\
1974 & $3-4$ & 33 & 14 & 19 \\
1975 & $2-3$ & 40 & 17 & 23 \\
1976 & $1-2$ & 42 & 20 & 22 \\
1977 & $0-1$ & 34 & 18 & 16 \\
Total & & 174 & 80 & $94^{*}$ \\
\hline
\end{tabular}

* Eighty-two of these patients had been removed from the trial and started on treatment with non-sulphone drugs. 
These had received weekly dosage of dapsone (usually 200 or $300 \mathrm{mg}$ ) before the trial (or were changed to daily dosage 6 months or less before the start of the trial).

"Daily dosage" group (130 patients).

These had received dapsone in daily dosage (usually $100 \mathrm{mg}$ ) for more than 6 months prior to the start of the trial.

Of the 25 patients who were doing well when assessed after 3 or more years of trial treatment, 17 were in the weekly dosage group; the other 8 , though included in the daily dosage group, had been changed from weekly to daily dosage only 12-15 months before the start of the study. These two groups of patients can be divided into cohorts according to the number of months they were studied. During each period a patient might show clinical deterioration (usually with removal from the trial); improvement and continue in the trial; or improvement but be "lost" from the trial because he was last assessed during this period. This analysis is summarized in Table 4, confirming that the weekly dosage group of patients improved for much longer than did the daily dosage group.

Although most patients in the trial were treated with dapsone $100 \mathrm{mg}$ daily (oral) 24 received dapsone by injection $(375 \mathrm{mg}$ weekly, suspended in $1.5 \mathrm{ml}$ hydnocarpus oil). Despite the lower dosage of dapsone, they did no worse than the rest of the patients. The hydnocarpus oil is unlikely to have been therapeutically active, as the recommended dosage is at least $15 \mathrm{ml}$ weekly (Cochrane, 1959).

TABLE 4

Number of patients still improving clinically after different periods of trial treatment

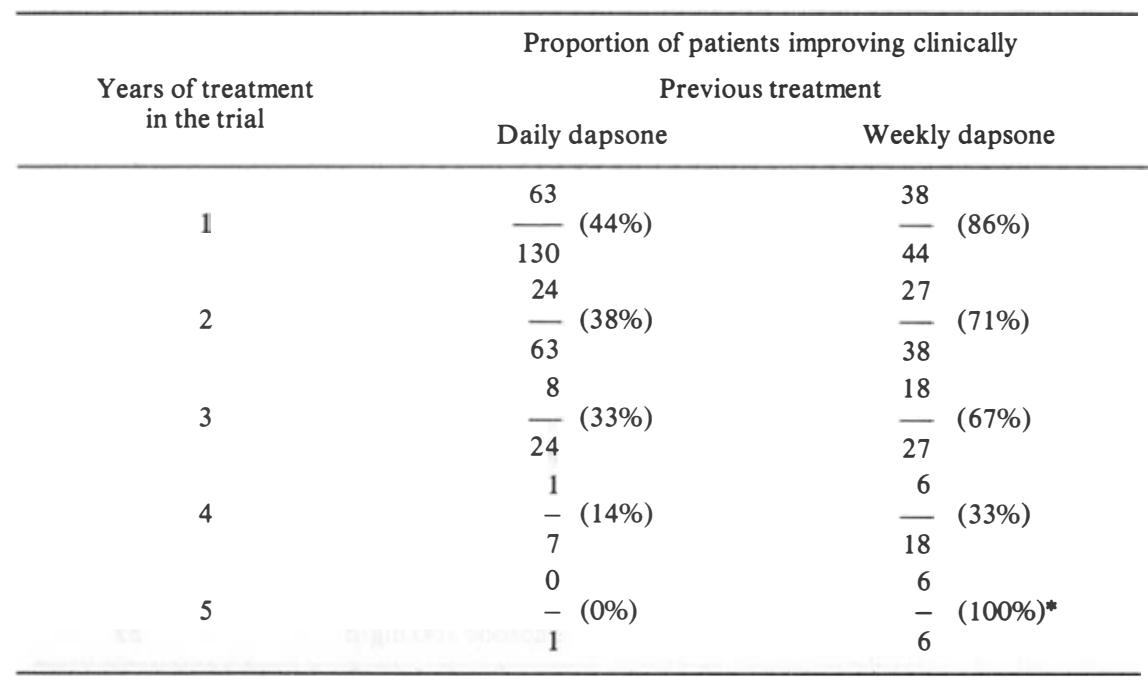

* Four of these patients have mouse foot-pad proof of dapsone-resistant leprosy (see Table 7). 
TABLE 5

Results of mouse foot-pad tests for dapsone resistance in 93 patients

\begin{tabular}{|c|c|c|c|}
\hline \multirow[b]{2}{*}{ Degree of resistance } & \multicolumn{3}{|c|}{ Number of patients tested } \\
\hline & $\begin{array}{c}\text { Trial } \\
\text { patients }\end{array}$ & $\begin{array}{l}\text { Other } \\
\text { patients }\end{array}$ & Total \\
\hline Resists dapsone $0.01 \%$ in mouse diet & 9 & 11 & 20 \\
\hline Resists dapsone $0.001 \%$ in mouse diet & 2 & 3 & 5 \\
\hline Resists dapsone $0.0001 \%$ in mouse diet & 3 & 12 & 15 \\
\hline Resistant, not fully titrated & 15 & 33 & 48 \\
\hline Sensitive to dapsone & 2 & 3 & 5 \\
\hline Total number of patients treated & 31 & 62 & 93 \\
\hline
\end{tabular}

The results of mouse foot-pad tests are shown in Table 5, both for this group of trial patients and for all Ethiopians tested in the period 1973-77. Of 93 patients tested, only 5 proved to be dapsone sensitive. The history and clinical features of the whole group conformed to the pattern of the trial cases: it is therefore likely that, despite their initial response to dapsone, the majority of the 92 patients continuing in the trial would prove to be resistant on further follow-up. Indeed, 4 of them showed mouse foot-pad proof of dapsoneresistant leprosy, though they had improved for 2.5 years or more (see Table 6).

\section{(2) Patients treated outside Addis Ababa}

One hundred and six patients were included in this group, all with lepromatous leprosy. The results of mouse foot-pad tests on $29(27 \%)$ of these patients are shown in Table 7; only one patient proved to be dapsone sensitive.

Fifty-six patients were advised to continue dapsone treatment for a trial period. The results of this trial at review early in 1978 were:

Those continuing in trial -15 , changed treatment -20 and defaulted -21 .

These results are hard to interpret precisely. The trial was unsupervised, and the abnormal conditions in the countryside which resulted from the political situation during this period often made "defaulting" inevitable. However, 97\%

TABLE 6

Duration of response to treatment in 4 patients with dapsone-resistant leprosy proven by mouse foot-pad tests

\begin{tabular}{cllc}
\hline $\begin{array}{c}\text { Case } \\
\text { no. }\end{array}$ & $\begin{array}{c}\text { Level of } \\
\text { resistance* }\end{array}$ & $\begin{array}{c}\text { Trial treatment } \\
\text { (weekly, w; daily, d) }\end{array}$ & $\begin{array}{c}\text { Duration of } \\
\text { response } \\
\text { (months) }\end{array}$ \\
\hline 1 & $0.0001 \%$ & Inj. dapsone $375 \mathrm{mg} / \mathrm{w}$ & 30 \\
2 & $0.0001 \%$ & Inj. dapsone $375 \mathrm{mg} / \mathrm{w}$ & 37 \\
3 & $0.001 \%$ & Inj. dapsone $375 \mathrm{mg} / \mathrm{w}$ & 49 \\
4 & $0.01 \%$ & Tab. dapsone $100 \mathrm{mg} / \mathrm{d}$ & 53 \\
\hline
\end{tabular}

* Percentage of dapsone in diet that inhibited growth of $M$. leprae in the mouse foot-pad. 
TABLE 7

Results of mouse foot-pad tests on 106 patients with "classical" dapsone-resistant leprosy from outside Addis Ababa

\begin{tabular}{lcccc}
\hline & \multicolumn{4}{c}{ Number of patients } \\
Clinical management & Resistant & Sensitive & Not tested & Total \\
\hline Changed treatment at once & 16 & 1 & 33 & 50 \\
$\begin{array}{l}\text { Started on trial treatment } \\
\quad \text { with dapsone }\end{array}$ & 12 & 0 & 44 & 56 \\
$\quad$ Total & 28 & 1 & 77 & 106 \\
\hline
\end{tabular}

(28 out of 29) of the mouse foot-pad tests showed dapsone-resistant strains of $M$. leprae. This indicates that most of the patients in this group were infected with dapsone-resistant organisms.

\section{ATYPICAL PRESENTATIONS OF SUSPECTED DAPSONE-RESISTANT LEPROSY}

Fifty-eight patients were studied, 34 from Addis Ababa and 24 from elsewhere in Ethiopia. Thirteen patients, however, defaulted, and are excluded from this analysis. The 45 patients may be grouped thus:

"Relapse cases" (new lesions developing after stopping treatment)--17, "solitary leproma of the eye"--4, "late reversal reaction"-8, "late ENL reaction"- 4 and "slow improvement"- 12 .

\section{(1) Relapse cases}

Seventeen lepromatous patients (13 of whom lived in the Addis Ababa area) were studied. All had received dapsone for periods of 2-16 years (average 8 years), and had then stopped treatment for 1-5 years. All 17 had a positive BI (average 4.1): in 14 the MI was positive, and 2 of the remaining 3 cases showed histological activity. Eleven were classified BL, LI or LL, one Indeterminate (though the BI was 2.2) and one was not biopsied.

All these patients were advised to take dapsone for a period of trial treatment. The outcome of this trial is shown in Table 8. Eleven patients showed evidence (clinical, mouse foot-pad, or both) of dapsone-resistant

TABLE 8

Outcome of trial treatment and results of mouse foot-pad tests in 17 relapse cases

\begin{tabular}{lc}
\hline \multicolumn{1}{c}{ Outcome } & $\begin{array}{c}\text { Number of } \\
\text { patients }\end{array}$ \\
\hline Dapsone resistant (mouse foot-pad tests) & 7 \\
Dapsone sensitive (mouse foot-pad tests) and removed from trial & 2 \\
$\begin{array}{l}\text { Deteriorated clinically during trial treatment (mouse foot-pad tests not } \\
\text { performed) }\end{array}$ & 4 \\
Improving under trial treatment (mouse foot-pad tests not performed) & 4 \\
\hline
\end{tabular}


TABLE 9

Clinical findings in patients developing reversal reaction later than usual in the course of dapsone treatment

\begin{tabular}{|c|c|c|c|c|c|c|c|c|c|c|c|}
\hline \multirow[b]{2}{*}{$\begin{array}{c}\text { Case } \\
\text { no. }\end{array}$} & \multicolumn{3}{|c|}{ Findings prior to reaction } & \multicolumn{3}{|c|}{$\begin{array}{c}\text { Findings at onset } \\
\text { of reaction }\end{array}$} & \multicolumn{5}{|c|}{ Findings following reaction } \\
\hline & $\begin{array}{l}\text { Classification } \\
\text { (clinical) }\end{array}$ & $\begin{array}{l}\text { Treatment } \\
\text { (years) }\end{array}$ & $\mathrm{BI}$ & BI & MI & Biopsy & $\begin{array}{c}\text { Steroid } \\
\text { treatment }\end{array}$ & $\begin{array}{c}\text { Duration } \\
\text { (years) }\end{array}$ & BI & MI & Biopsy \\
\hline 1 & $\mathrm{~L}$ & 13 & 0 & 2.3 & 0 & BT & None & 1.5 & 3.5 & 4 & $\mathrm{BL}^{*}$ \\
\hline 2 & $\mathrm{~L}$ & 7 & 1.7 & 1.8 & 0 & BT & None & 1.5 & 2.6 & 1 & $\mathrm{LL}$ \\
\hline 3 & $\mathrm{~L}$ & 13 & $\mathrm{NA} \dagger$ & 3.3 & 0 & BB & None & 3 & 1.8 & 0 & $\mathrm{~L} / \mathrm{ENL}$ \\
\hline 4 & $\mathrm{~L}$ & 4 & 0 & 3.5 & 0 & $\mathrm{BB} / \mathrm{BT}$ & None & 3 & 0.5 & POS & Indet. \\
\hline 5 & $\mathrm{~L}$ & 8 & 0 & 2.7 & 1 & $\mathrm{BT} / \mathrm{BB}$ & None & 3 & 0.7 & 0 & NA \\
\hline 6 & $\mathrm{~L}$ & 7 & 0 & 1.2 & 0 & BL-BT & None & 2.5 & 0.6 & 0 & NA \\
\hline 7 & $\mathrm{BL}$ & 4 & 0 & NA & NA & BB-BT & Given & 1 & 0 & - & Indet. \\
\hline 8 & $\mathrm{BL}$ & 4 & 0 & 3.8 & 1 & BB & None & 2 & 1.8 & 0 & NA \\
\hline
\end{tabular}

*Foot-pad tests showed dapsone resistance at $0.001 \%$ dapsone in the mouse diet (but sensitive at $0.01 \%$ ). After 2.5 years continued monotherapy with dapsone the disease was clinically quiescent, $\mathrm{BI}=0$, Biopsy $=$ Indeterminate.

$\dagger \mathrm{NA}=$ Not available.

$\mathrm{POS}=$ Positive, figure not available. 
leprosy; and of the 4 patients improving under trial treatment who did not have mouse foot-pad tests performed, 3 were followed up for a year or less.

\section{(2) Solitary leproma of the eye}

Lepromata of the eye were noted in about $5 \%$ of patients with suspected dapsone-resistant leprosy. There were, however, 4 patients in whom an ocular leproma was the sole evidence of active leprosy. The BI was positive (0.5-2.7) in all 4 cases, though the MI was 0 , and clinically the disease appeared to be quiescent in the skin. Following treatment with clofazimine (together with treatment of iridocyclitis if present) vision was preserved in 3 cases; the fourth was already blind. In one patient (together with another in whom skin nodules were also present), the superficial part of the leproma of the eye was removed surgically, and used as a source of bacilli for mouse foot-pad inoculation. Both cases proved to be dapsone resistant.

\section{(3) Reversal reaction occurring later than usual in the cour se of treatment}

We have studied 8 patients in this category; all of them had previously been classified as lepromatous, and had been treated for 4 or more years. The BI had been reported negative in 6 cases. They all presented with the appearance of new lesions which, both clinically and histologically, were in the borderline range.

Although the appearance of BB or BT lesions in a previously lepromatous patient must be categorized as reactional, only one patient showed sufficiently active lesions and neuritis to warrant the use of corticosteroids. The remainder were treated with dapsone in full dosage. The results of this trial are shown in Table 9. In 2 patients (cases 1 and 2) the BI rose and the classification downgraded to lepromatous; in one of them mouse foot-pad tests showed dapsone resistance. In a third (case 3) the BI fell, but the appearance of ENL lesions indicated that downgrading had occurred. It is likely that these 3 patients were dapsone resistant. In addition, case 4, though apparently improving, still showed occasional solid staining bacilli in skin smears when last assessed.

In the remaining 4 patients the lesions resolved, the BI fell, and the disease became quiescent once more (one of these patients received steroid treatment for his reaction). It would be tempting to consider them as dapsone sensitive. However, the patient with proved dapsone resistance responded well to dapsone monotherapy (after initially downgrading from BT to BL); 4 years after the appearance of his lesions he was clinically quiescent, $\mathrm{BI}=0$, and histologically Indeterminate. Much longer follow-up would therefore be required to say confidently that these 4 patients were dapsone sensitive.

\section{(4) ENL reactions occurring later than usual in the course of treatment}

Four patients were studied in whom an attack of ENL was the first indication of possible recrudescence of disease. Three patients had been found smear negative during the year preceding the reaction; the fourth (case 1) had 
TABLE 10

Clinical data of 4 patients developing erythema nodosum leprosum (ENL) later than usual during treatment

\begin{tabular}{ccccccccc}
\hline & \multicolumn{6}{c}{ Prior to onset of ENL } & \multicolumn{5}{c}{ At time of ENL } & Outcome \\
$\begin{array}{c}\text { Case } \\
\text { no. }\end{array}$ & $\begin{array}{c}\text { Treatment } \\
\text { (years) }\end{array}$ & SI & MI & BI & MI & $\begin{array}{c}\text { Duration } \\
\text { of ENL } \\
\text { (months) }\end{array}$ & Treatment \\
\hline 1 & 10 & 3.0 & 0 & 3.3 & 0 & 6 & Dapsone & $\begin{array}{c}\text { Improved at } \\
4 \text { years }\end{array}$ \\
2 & 6 & 0 & - & 0.7 & 0 & 3 & Dapsone $\begin{array}{c}\text { Improved at } \\
\text { 2 years }\end{array}$ \\
3 & 6 & 0 & - & 5.4 & 3.0 & 2 & $\begin{array}{c}\text { Slofazimine Improved at } \\
\text { 2 years }\end{array}$ \\
4 & 8 & 0 & - & 0 & - & 1 & Dapsone & $\begin{array}{c}\text { Improved at } \\
\text { 1 year }\end{array}$ \\
\hline
\end{tabular}

shown a slowly rising BI for the previous 2 years, but his disease looked inactive.

The clinical findings of this group of patients are shown in Table 10. Mouse foot-pad tests were not performed in any of them (and would indeed only have been possible in case 3). Case 3 received clof azimine because of severe ENL: the combination of ENL and a raised MI makes it likely that he was dapsone resistant. The other 3 patients showed no evidence of resistance after 1-4 years follow-up.

\section{(5) Apparent slow improvement under treatment with dapsone}

Twelve lepromatous patients were studied in whom an apparent slow improvement had led to suspicion of resistance. They said they had "never really improved", but in most cases the clinical records were inadequate to confirm this statement. The period of treatment ranged from 1 to 14 years.

The BI was positive in all cases, but the MI raised only in 6 (Table 11). Mouse foot-pad tests were set up in 2 patients; one of them was fully sensitive, the other showed high grade DDS resistance. An additional patient relapsed under trial conditions. The remaining 9 were doing satisfactorily, when followed up for periods of 3-25 months.

\section{PRIMARY DAPSONE-RESISTANT LEPROSY}

Mouse foot-pad tests were undertaken in 29 patients with previously untreated lepromatous leprosy. They had lived for many years in Addis Ababa or other areas of Ethiopia where dapsone treatment had been regularly available for 10 or more years, but were otherwise unselected. More than half (16 out of 29) of them showed primary dapsone-resistant leprosy (Table 12) indicating that some years previously, when these patients were infected, about half the infectious index cases were already suffering from sulphone-resistant 
TABLE 11

Clinical data of 12 patients apparently responding slowly to treatment with dapsone and outcome following trial treatment

\begin{tabular}{rccccccc}
\hline $\begin{array}{c}\text { Case } \\
\text { no. }\end{array}$ & $\begin{array}{c}\text { Previous } \\
\text { treatment } \\
\text { (years) }\end{array}$ & BI & MI & Biopsy & $\begin{array}{c}\text { At start of trial } \\
\text { foot-pad } \\
\text { tests }\end{array}$ & $\begin{array}{c}\text { Trial of } \\
\text { treatment } \\
\text { (months) }\end{array}$ & Outcome on follow-up \\
\hline 1 & 2 & 3.2 & 2.0 & *NA & Fully resistant & 9 & Deteriorated, changed treatment \\
2 & 10 & 4.7 & 0.5 & NA & NA & 17 & Deteriorated, changed treatment \\
3 & 1 & 4.1 & 6.0 & LL & Fully sensitive & 12 & Improving \\
4 & 2 & 5.0 & 1.0 & Ls & NA & 23 & Improving \\
5 & 10 & 3.5 & 4.0 & LI & NA & 3 & Improving \\
6 & 5 & 3.7 & 4.0 & BL & NA & 3 & Improving \\
7 & 3 & 4.0 & 0 & BL & NA & 25 & Improving \\
8 & 11 & 0.8 & 0 & LL & NA & 12 & Improving \\
9 & 4 & 1.7 & 0 & NA & NA & 12 & Improving \\
10 & 14 & 1.3 & 0 & Idt & NA & 8 & Improving \\
11 & 2 & 5.3 & 0 & Lp & NA & 4 & Improving \\
12 & 2 & 3.7 & 0 & NA & NA & 3 & Improving \\
\hline
\end{tabular}

${ }^{*} \mathrm{NA}=$ Not available. 
TABLE 12

Results of mouse foot-pad tests on 29 previously untreated patients with lepromatous leprosy tested for primary dapsone-resistant leprosy

\begin{tabular}{|c|c|c|}
\hline \multirow[b]{2}{*}{ Result of foot-pad test } & \multicolumn{2}{|c|}{ Number of patients } \\
\hline & $\begin{array}{c}\text { Living in } \\
\text { Addis Ababa }\end{array}$ & $\begin{array}{l}\text { Living } \\
\text { elsewhere }\end{array}$ \\
\hline Sensitive & 9 & 4 \\
\hline Resists $0.0001 \%$ dapsone in diet & 2 & 4 \\
\hline Resists $0.001 \%$ dapsone in diet & 1 & 3 \\
\hline Resists $0.01 \%$ dapsone in diet & 0 & 1 \\
\hline Resistant, not fully titrated & 2 & 3 \\
\hline
\end{tabular}

leprosy. The proportion of primary resistance among patients living outside Addis Ababa was at least as high as that found in Addis Ababa itself.

\section{Discussion}

\section{GENERAL}

A number of conclusions can be drawn from this study.

(1) In the Addis Ababa area the incidence of new cases of suspected dapsoneresistant leprosy is about 3\% per year of registered lepromatous cases, and the great majority of these are truly resistant.

(2) Most patients referred from outside Addis Ababa with suspected acquired dapsone resistance have also proved to be resistant when it has been possible to carry out tests adequately.

(3) The proportion of patients with primary dapsone-resistant leprosy is no less in centres outside Addis Ababa than it is among patients living in the Addis Ababa area.

It is therefore certain that dapsone-resistant leprosy is widespread throughout Ethiopia. A high prevalence of such cases is serious in itself: each patient demands considerable outlay of resources for diagnosis and long term treatment. But the more serious aspect of the problem is that these cases can become epidemiologically significant; that is, they become the index cases for a significant number of patients with primary dapsone-resistant leprosy. It is hard to define the point at which this occurs: a consensus might settle for about 5\% primary resistance as a figure which, if exceeded, would be epidemiologically alarming. It is certain, however, that our figure of about $50 \%$ of primary dapsone-resistant leprosy indicates a major defeat for the policy of attempting to control leprosy by chemotherapy with dapsone alone.

The degree of dapsone resistance shown by a strain of $\boldsymbol{M}$. leprae depends chiefly on the dosage of dapsone the patient is receiving. Low dosage permits low grade resistant bacilli to multiply, but high dosage prevents all but high grade resistant mutants from multiplying. Thus weekly and often low dosage of dapsone was employed in Ethiopia till about 1975; therefore the majority of patients with primary dapsone-resistant leprosy identified prior to 1978 show low grade resistance. It may be anticipated that the daily and usually higher 
total dosage employed from about 1975 on will ensure that in future a larger proportion of strains of $M$. leprae will show high grade dapsone resistance.

\section{“CLASSICAL” DAPSONE RESISTANCE}

This remains the most common presentation of suspected acquired dapsone resistance, accounting for $83 \%$ of all cases in this series. The results of this outpatient study differ in several ways from those reported from hospitalized patients with "classical" histories (Pearson et al., 1975).

(1) Our patients developed resistance more rapidly (2-20 years, peak at 7-11 years),

(2) Our patients responded for longer under trial treatment with dapsone (at least $15 \%$ for 3 years or more),

(3) Some $5 \%$ of our patients proved to be dapsone sensitive on mouse footpad tests.

These differences are most probably related to the uncertainties of both history and therapy during out-patient treatment. In addition, patients developing resistance very rapidly may well have been suffering from low grade primary dapsone-resistant leprosy.

When patients have previously received irregular (or weekly) treatment, they are likely to experience a prolonged remission on regular monotherapy with dapsone. Such patients are not proved sensitive even if still improving under reasonably supervised treatment after 2 or 3 years. This indicates that they usually have low grade dapsone resistance, and that dapsone in full dosage often remains efficacious. There would be a good case for treating such patients with dual therapy (dapsone plus a second drug) for a year or two when they are first seen: such a regimen, followed by dapsone monotherapy, might often prove curative.

\section{RELAPSE PATIENTS}

One of the unexpected findings of this trial was that out of 17 relapse patients tested, 11 showed clinical or foot-pad proof of dapsone resistance. If these results are confirmed by studies elsewhere, it will indicate that all relapse cases should receive dual or triple therapy for a year or two when they restart treatment, in the hope that continued monotherapy with dapsone thereafter may be curative.

\section{LEPROMATA OF THE EYE}

The eye is an unusual site to find nodules in previously untreated leprosy. It is, however, a fairly common site in patients with acquired dapsone-resistant leprosy. Patients with this complication often develop severe and prolonged iridocyclitis; they should, therefore, be changed to treatment with another drug combination as soon as the leproma is observed, rather than undergoing a period of trial treatment with dapsone.

The nodules are usually on the lateral aspect of the corneoscleral junction, and encroach on the cornea only very slowly. The superficial part of the nodule can readily be sliced off under local anaesthetic. It is full of bacilli, 
which can be used for mouse foot-pad inoculation. If there are no nodules elsewhere on the body, this is the only reliable way to prove dapsone resistance.

\section{REVERSAL REACTION OF LATE ONSET}

Most patients who develop reversal reaction do so within a year or two of first starting treatment: to develop reaction at a much later stage must lead to suspicion that the reaction has been triggered by bacillary multiplication and may therefore indicate the emergence of dapsone resistance.

Of the 8 patients we studied who developed reversal reaction after 4 or more years of treatment, 3 seem fairly likely to prove resistant, and in a fourth case there is foot-pad proof of resistance despite a prolonged remission under trial treatment with dapsone. Only one patient, however, developed reaction severe enough to warrant corticosteroid therapy: the others, though previously (and correctly) classified as lepromatous, presented with lesions that were clinically and histologically in the borderline range. This may be the same process that occurs during the development of lepromatous leprosy prior to treatment. Patients with lepromatous leprosy will often give a history of initially localized lesions which, from the description, appear to have been in the borderline range; they describe subsequent spread of the disease, which downgrades to lepromatous, with or without accompanying reactions. Three of the 8 patients in this group showed downgrading without overt reaction: it would be instructive to follow the clinical progress of the remainder. Patients in this category could well prove to be of unusual immunological interest.

Downgrading and upgrading within the $\mathrm{BL} / \mathrm{LL}$ range have also been observed in a number of female patients with probable dapsone-resistant leprosy in association with pregnancy. This phenomenon will be reported fully elsewhere.

\section{ENL OF LATE ONSET}

In the patients we studied this appeared to be of little or no value as evidence of the emergence of dapsone-resistant leprosy. Moreover, the MI in such patients is usually zero, so mouse foot-pads will seldom be successful: proof of resistance must be by clinical trial. However, the combination of ENL and a persistently raised MI is likely to indicate dapsone resistance.

\section{APPARENT SLOW IMPROVEMENT UNDER TREATMENT WITH DAPSONE}

It is hard to interpret these findings, though case 1 seems to be a case of primary dapsone-resistant leprosy, and case 2 of acquired resistance. Much longer periods of follow-up would be needed to assess whether or not the remaining patients were in an early stage of incubation of dapsone-resistant leprosy, or whether they were merely irregular tablet takers. 


\section{Acknowledgements}

We are grateful to colleagues working in the All Africa Leprosy and Rehabilitation Training Centre (ALERT) and in the National Leprosy Control Programme, who referred patients for assessment and contributed to their management. Facilities for patient care and treatment were provided by the Addis Ababa Leprosy Hospital, and for mouse foot-pad tests in Ethiopia by the Armauer Hansen Research Institute. We thank Dr D. S. Ridley for independent histological assessments. We are indebted to Mrs Gillian Foskett and Mrs Joyce Reittie for technical assistance in the studies undertaken at the National Institute for Medical Research, London.

Part of the costs of the study on primary dapsone-resistant leprosy was covered by a WHO Grant from the TDR/THELEP programme. GSH was partly supported by Medical Research Council Project Grant G975/171.

\section{Ref erences}

Cochrane, R. G. (1959). In Leprosy in Theory and Practice, 1st edit., p. 208. John Wright \& Sons, Bristol.

Pearson, J. M. H., Rees, R. J. W. and Waters, M. F. R. (1975). Sulphone resistance in leprosy: a review of one hundred proven clinical cases. Lancet 2, 69.

Pearson, J. M. H., Ross, W. F. and Rees, R. J. W. (1976). DDS resistance in Ethiopia-a progress report. Int.J. Lepr. 44, 140.

Pearson, J. M. H., Haile, G. S. and Rees, R. J. W. (1977). Primary dapsone resistant leprosy. Lepr. Rev. 48, 129.

Pettit, J. H. S. and Rees, R. J. W. (1964). Sulphone resistance in leprosy: an experimental and clinical study. Lancet 2, 673.

Rees, R. J. W. (1976). Drug resistance of Mycobacterium leprae, particularly to DDS. Int. J. Lepr. 35, 625. 